\title{
Opening up is not showing up: human volition after the pandemic
}

\author{
Daniel W. Bromley ${ }^{1}$ (D)
}

Received: 3 July 2020 / Accepted: 28 November 2020 / Published online: 3 January 2021

(C) The Author(s), under exclusive licence to Springer-Verlag GmbH, DE part of Springer Nature 2021

\begin{abstract}
A global pandemic on the scale of Covid-19 upsets all standard decision protocols. Pressure from politicians to "open up" the economy presumes that individuals grant credible trust to politicians and merchants eager to recover customers. The asymmetric concern for safety compounds normal heuristics. The Peircean pragmatic maxim reminds us that it is the perceived effects of a post-pandemic society and economy that will drive human volition in the aftermath of Covid-19. Opening up does not equal showing up.
\end{abstract}

Keywords Volition · Created imaginings · Pandemic · Trying-undergoing · Habituation

\section{On going in}

We have never done this before. Habituated protocols and heuristics for human action are of no value. Bayesian algorithms offer no help. Ordinary risk assessment is of middling assistance. Uncertainty reigns. We are confused.

This novel mélange of decision points-motivated by a different sort of novelty-is layered and contested. Who may (must) decide when a private business should (must) close? Who must (may) decide what to do when that act is contested by others? How do those questions vary when the subject is not a private business but is a religious house, a municipal facility, or a local chess club? The menu of necessary or volitional actions in the face of an approaching threat of a completely unknown nature is a wonder to behold. When consideration is then paid to an individual perspective versus a collective perspective, clarity dissipates. We have never done this before.

Daniel W. Bromley

dbromley@wisc.edu

1 Anderson-Bascom Professor of Applied Economics (Emeritus), University of Wisconsin-

Madison, Madison, USA 
But this is the easy part. After all, the above actions are motivated by a shared purpose to contain impending harm. There is a common enemy to be vanquished. Once all of the manifold considerations have been debated, weighed, reconsidered, disputed, and then finally undertaken, a new constellation of actions descends - and the wait for deliverance begins. All participants in this imposed re-constitution of familiar social arrangements — of new habits - will hold an array of views regarding the multitude of necessary adjustments. Each of us, with little residual autonomy in a global pandemic, is pushed and pulled, with varying degrees of mental reservation (and some minor bouts of open resistance), into a rather harmonized corps. We become coerced comrades - conscripts - in the struggle. Very few individuals agreed to those new protocols-local and national officials were the authoritative agents in the closing down. But virtually everyone must come to agree with those protocols. After all, we have little choice.

Out of this social experiment, new habits will give rise to new shared norms of behavior. As John Dewey reminded us, we do not "take" new habits. We are our habits.

\section{On coming out}

The coming out part will be profoundly different from the going in part. The common enemy is now defeated-or we believe it to be in retreat. Now what? Notice that unlocking is not at all like locking down. There are three reasons for this difference.

The first is a product of the battle at hand. The going-in part-locking down-was driven by a plausible set of epidemiological models and empirical protocols concerning vector-host interactions and patterns, the wiliness and efficacy of the biological agent, the likely constellation and readiness of health-care facilities and staffing, and other factors pertinent to the behavior of similar agents. The purpose of locking down was to isolate the multitude of very attractive new hosts from the threatening proximity of the feared agent. And the locking down had the heavy hand of the state behind it.

However, the unlocking is not that way at all. The coming out is an act of official permission rather than official prohibition. And permission is not simply the converse of prohibition. Our individual and collective responses to permission will, therefore, be very different. Recalling the fundamental Hohfeldian legal correlates, rather than must and must not, we now face may and can [Bromley 2006]. But notice as well that the prohibitions (must and must not) remain as conditionals under the new dispensation. That is, newly accessible facilities (venues) must follow certain protocols, and they must not allow certain actions to occur. This constellation of new permissions cum proscriptions further confounds new fields of action-choice sets-and thus behaviors.

While the locking down entailed no scope for volition, the coming out part is nothing but volition-mediated by yet a new constellations of prohibitions on both sides of every interaction. It will be a volition dominated by two versions of indeterminacy_of may and can, but also of must and must not. 


\section{The problematic volition}

Consider what effects,...we conceive the object of our conception to have. Then, our conception of these effects is the whole of our conception of the object [Peirce 1992, p. 1].

A second problem concerns novel perceptions of the new decision space. Charles Sanders Peirce reminds us - in the above pragmatic maxim - that our perceptions of the world out there are simply the sum of our perceptions of the effects that world has on us. But, of course, those apprehended perceptions - those effects-are themselves highly problematic. G.L.S. Shackle pointed out that when we begin to undertake a novel act, we are confronted with a difficult realization-we have never done that before. This brings us to an interesting pass. Simply put, "Outcomes of available actions are not ascertained but created...An action which can still be chosen or rejected has no objective outcome. The only kind of outcome which it can have exists in the imagination of the decision-maker [Shackle 1961, p. 143]." (emphasis in original).

The exhilaration of reentering the new Covid-laden world is an act of volition that leaves each of us focused on the Peircean "effects" as the sum total of our perceptions of what that new world will be. And since we have no experience with that world, we are necessarily prisoners of our created imaginings about it. Dewey insisted that "...each conflicting habit and impulse takes its turn in projecting itself upon the screen of imagination [Dewey 1922, p. 190]." We can only imagine that world, and how we shall negotiate our way into it, and through it. We have never done this before.

\section{We are no longer who we were}

Finally, the volitional agent, eager to re-engage the world, is no longer the same agent who was forced to endure the original imposition of must and must not. That is, the imposed lockdown constitutes a Deweyan trying. But, on coming out at the other end, the reluctant subjects of that imposed ruling are now the newly recreated-reconstituted-objects of Deweyan undergoing. As Dewey pointed out:

The nature of experience can be understood only by noting that it includes an active and a passive element peculiarly combined. On the active hand, experience is trying-a meaning which is made explicit in the connected term experiment. On the passive, it is undergoing. When we experience something we act upon it, we do something with it; then we suffer or undergo the consequences. We do something to the thing and then it does something to us in return; such is the peculiar combination. The connection of these two phases of experience measures the fruitfulness or value of the experience. Mere activity does not constitute experience. It is dispersive, centrifugal, dissipating. Experience as trying involves change, but change is meaningless transition unless it is consciously connected with the return wave of consequences which flow from it. When an activity is continued into the undergoing of consequences, when the change made by action is reflected back into a change 
made in us, the mere flux is loaded with significance. We learn something [Dewey 1916, p. 139].

We see here Dewey's challenge to the standard psychological explanation of the reflex arc. In that 1896 paper, a young Dewey, just 37, offered what many experts believe to be his most significant contribution to psychology - a challenge to the stimulus-response model of human action. Dewey argued that a child, singed by a candle flame, quickly withdraws her hand. He insisted that the stimulus (heat) was separable from the response (withdrawal). Dewey understood that the process was not linear but circular - an important variety of learning was taking place. With that being the case, cause and effect are more difficult to disentangle. Of course the light of the candle was an attractant to the child. However, Dewey insisted that the real beginning was not the mental process of attraction to the flame. Rather it was the mere seeing. He insisted that it is the looking that matters, not the light that is then seen. The seeing and reaching are not distinct but are part of the above "coordination problem." Reaching and seeing — or seeing and reaching-help each other out. The hand and the eye are part of the same internal act of sapience. Seeing is not just for seeing. Seeing is for reaching.

When a particular activity is continued into the undergoing of consequences a change that we have made is reflected back into a change made on us. We make choices and undertake actions that, when followed through, require that we undergo consequences. But those consequences are reflected back in the form of changes made on us. Those changes do not simply bounce off of us-they become part of us. We learn something and we are therefore changed. Unlike the simple reflex arc, in which a child withdraws her hand and then moves on wiser but unchanged, the child is changed in a number of ways - not just in her aversion to a flame. She becomes a different person by experiencing the unpleasant consequences of her seeing.

\section{Arriving at new beliefs-acquiring new habits}

Belief does not make us act at once, but puts us into such a condition that we shall behave in some certain way, when the occasion arises. Doubt has not the least such active effect, but stimulates us to inquiry until it is destroyed [Peirce 1957, p. 11].

We see three aspects of this exercise in imposed social isolation. First, the experience of going into such isolation is profoundly different from the experience of coming out. Second, once the isolation has been lifted, and the newly liberated agent is able to re-engage the world, requisite behavioral heuristics and protocols will have been stripped of their relevance for the post-lockdown world. Since the agent's perceptions of the world to be re-engaged are necessarily limited to the novel impressions of the array of effects of that world back on the agent, it will take time to apprehend and process those novel effects. Finally, and most importantly, recipients of those novel effects - the newly liberated agent-will be confused about the nature and meaning of those effects because the agent is now cognitively distinct from the agent upon whom the imposed trying created its unwitting undergoing.

The more interesting implication of this imposed undergoing is that it sets the stage for a quite novel reassessment of what is normal, customary, and therefore 
right [Bromley 2019]. New collective rules to live by are ordinarily the result of long bouts of frustration, discord, contestation, political back-and-forth, and bitterness. Think climate change, the fight over genetically modified organisms, and the provision of public health programs. The mental vortex of imposed institutional changea lockdown-compresses this process by the obligation to try something new, and that trying forces an undergoing. With the inertia of many customary mental frames shattered, much brush has been cleared away. New seeds can now more easily take root. However, we remain unsure as to what might flower.

\section{Complaince with ethical standards}

Conflict of interest I verify that there is no conflict of interest associated with this manuscript

\section{References}

Bromley DW (2006) Sufficient Reason: Volitional Pragmatism and the Meaning of Economic Institutions. Princeton University Press, Princeton

Bromley DW (2019) Possessive Individualism: A Crisis of Capitalism. Oxford University Press, Oxford Dewey J (1916) Democracy and Education. Macmillan, New York

Dewey J (1922) Human Nature and Conduct: An Introduction to Social Psychology. Holt, New York

Peirce CS (1992) How to make our ideas clear. In: Houser N, Kloesel C (eds) The Essential Peirce, vol 1 (1867-1893). Indiana University Press, Bloomington, p 132

Peirce CS (1957) Essays in the Philosophy of Science. The Liberal Arts Press, New York

Shackle GLS (1961) Decision, Order, and Time in Human Affairs. Cambridge University Press, Cambridge

Publisher's Note Springer Nature remains neutral with regard to jurisdictional claims in published maps and institutional affiliations. 